Journal of Fandom Studies Special issue, edited by C. Lee Harrington and Matt Hills: Fandom and the Life Course

\title{
Editorial
}

\section{Introduction: Fandom from Cradle to Grave?}

\section{Matt Hills, University of Huddersfield}

The work of C. Lee Harrington and Denise Bielby (e.g. 2010 and 2018) has been significant in focusing the attention of fan studies' scholars on matters of the life course that is, the sociological, cultural and institutionalised construction of different phases of life, from childhood through education to adulthood, employment, and across various stages of later life. Writing almost a decade ago, Harrington and Bielby forcefully argued that

\footnotetext{
what is missing from contemporary fan studies... is explicit consideration of life course perspectives that can help clarify and deepen our understanding of fans' sustained engagement with media objects over time and the transformations of fandom in later life. We find surprisingly little engagement with aging and/or life course theory in fan studies (2010: 434).
}

At the time, this absence was especially surprising, given that a range of media franchises and texts had attracted long-term fandoms, with fan cultures and communities continuing to endure even after the cancellation or cessation of fan objects; this is something that Rebecca Williams (2015) has latterly theorised as "post-object fandom".

Returning to issues of fandom and the life course more recently, Harrington and Bielby have continued to emphasise the need for more analysis of what they term "texistence", or how "the self develops in ongoing dialogue with the media texts that help define and sustain it" (2018: 411). Indeed, the increased significance of fandom to (communally shared) self-narratives of identity unfolding over time has even been testified to by the positing of specific fannish generations, e.g. Marianne Martens discusses "the 
Harry Potter generation" as fans of the series "born between 1980 and 1996, who grew up reading the new books in the series each year as they were published" (2019: 32-33). And elsewhere I have analysed how lifelong Doctor Who fans, some of whom have followed the BBC TV sci-fi show since it began in 1963, have made new and varied meanings from the series as they have aged, and as they have entered new stages of the life course. Their fan object is used, actively, as a "life-transitional object", bridging, and sometimes smoothing over, developmental changes, and allowing for a constructed (yet naturalised) sense of selfcontinuity (Hills 2017).

Such work resonates with Harrington, Bielby and Bardo's observation that there has been a relative "de-institutionalization of the 20th-century life course" (2011: 570), as the life course has become more fluid, less anchored to things such as work (there may be few 'jobs for life' now), and more capable of individualised - if not neoliberalized/consumerist (Hall and O'Shea 2015) - navigation:

Pointing to increasingly 'liquid lives'..., life course scholars thus echo theorists elsewhere in the academy... in emphasizing an individualization thesis that characterizes the 20th-to-21st-century transition... Our central thesis is that the new landscape of fandom as documented in the West - its visibility and normalization - is a manifestation of this flexibility..., with the emotional anchoring provided through fandom supplanting the anchoring of the institutionalized life course. In other words, we argue that population aging and restructuring of the life course, on one hand, and the changing role of media and media fandom in people's lives, on the other hand, are dual processes that inform and shape one another (Harrington, Bielby and Bardo 2011: 571).

Of course, this does not mean that social concepts of age-appropriateness have completely dissolved, and fandom continues to negotiate these norms even whilst fans' "texistence" unfolds across life course transitions: "Adult fans hold themselves and others accountable to age norms, they struggle to justify and maintain fan practices given normative life course restraints, ...cognitive and bodily aging, and their own... mortality" (Harrington, Bielby and Bardo 2011: 584).

Exploring the complexities of fandom and the life course therefore means adopting a 
multi-dimensional approach whereby age-appropriate cultural norms might be normatively enacted or differentially 'resisted', as well as self-aging being performed in relation to (sometimes unpredictable) forms of the fan object's text-aging (or its "post-object" status). The life course thus becomes lived experience thanks to an array of microscopic and macroscopic intersections of the individual and communal, making this one aspect of what Sandvoss, Gray and Harrington (2017: 8) have described as the "third wave" of fan studies' scholarship, examining "the individual psychology of fandom within its wider social context".

However, to date this "third wave" has been marked by lacunae. Work on fandom and the life course has tended to bunch in mid-life (or 'early later life'), leaving the extremes of childhood meaning-making and end-of-life contexts somewhat untheorized; in different ways, these have been seen as difficult topics, no doubt, since they raise distinctive issues of research ethics/access as well as calling for specific sensitivities. Both these structuring absences in fan studies are addressed here, as we start with Kyra Hunting's much-needed analysis of child fans, and conclude with C. Lee Harrington's ground-breaking discussion of fandom in relation to the "U.S. death system".

Hunting analyses the obstacles to theorising children as fans - especially the possibility that children's consumption in general, with its repeated re-readings and brand loyalties, may resemble fandom tout court - as well as considering the difficulties posed by children not always utilising discourses of fandom. Nonetheless, Hunting argues for the value of including child fans in fan studies' expansion into under-studied communities and overlooked fan groups, as well as touching on the issue of parents and children possibly demonstrating shared co-fandoms.

Between Hunting and Harrington's bookending pieces, this issue adopts a sequence of different ways into fandom and the life course. Following on from Hunting's article, Line Nybro Petersen and Vilde Schanke Sundet look at the Norwegian teen drama SKAM (NRK, 2015-2017), analysing how "play moods" are negotiated across the life course by fans aged from 13 to 70, and hence considering how teen TV can find fans who do not fit into its ageappropriate, normative target audiences. Petersen and Sundet complicate normative understandings of the life course as marked by (more or less) institutionalized transitions by showing how fans' playfulness and "play moods" can sustain culturally-valued and subjectively youthful performativities even for those fans whose "chronological" ages would 
be viewed as far outside a 'youth' or 'teen' classification.

The next two articles both move on to look at pop music fans. Simone Driessen examines how adult fans consumed the reality TV series The Big Reunion (ITV2, 2013-2014); this was a show which sought to bring back together various boybands and girlbands from the 1990 s and early noughties. Driessen challenges negative stereotypes of aging pop music fans as merely nostalgic, showing how this devaluation of yesterday's pop does not correspond to the more nuanced and ironic ways in which former fans of the acts appreciate their attempted comebacks. However, Driessen demonstrates at the same time that for at least some of The Big Reunion fan viewers, adopting a critical (and self-critical) perspective on their youthful fandom means circulating age-appropriate norms through which 'teen' or 'childhood' fan self-identities are othered as "naïve". Forms of adult cultural power (and empowerment) can hence be problematically performed by devaluing a mode of teen fandom that is seen as belonging to a previous stage in the life course.

Matt Hills continues the focus on popular music fandom by analysing how the career of the British synthpop duo Pet Shop Boys (PSBs) has been self-theorised by former music journalist and PSB vocalist Neil Tennant as amounting to an immediate "imperial" phase of 1980s chart hits and number ones, followed implicitly by a post-imperial and hence more niche, fannish durability. Hills shows how long-term (and now mid-life or "third age") fans have drawn on this narrative of "text aging", in some cases nostalgically hoping for a return to the smash hits of yesteryear, but also narrating the text of the PSBs as one of enduring and current pop energy. Fans have thereby resisted age-appropriate norms by positing PSB's ongoing pop releases as the attainment of "successful" text aging which reflects on this neoliberal, consuming fandom itself.

The final two articles of the issue shift tack to look at fandom in later-life. Joseph Andrew Smith draws on interviews with 35 participants in their own homes (or in a care home), with the average age of interviewees being 72.5 years old. These respondents, in the "third" or "fourth" ages of retirement or frail physical health, discuss their sports fandoms, with Smith applying a form of gerontological analysis known as "continuity" theory to his data. This enables a study of how these fans adapt and maintain their fan practices in a variety of ways, despite perhaps not being able to attend football or rugby matches in person any longer, or not being able to clearly see games on TV. Rather than these challenges/destabilisations resulting in a loss or reduction of fandom, Smith demonstrates 
how, for these sports fans, an ongoing sense of self-continuity is discursively and experientially attained.

Lastly, C. Lee Harrington develops the study of fandom and aging by examining fan identities in an end-of-life context, asking whether and how fan practices remain salient to people here. Drawing on both gerontology and thanatology, Harrington considers fandom in relation to the "U.S. death system", i.e. that constellation of institutions and symbolic networks through which an individual's relationship to their mortality is socially mediated, including the likes of wish foundations and funeral companies. Although Harrington chose not to directly interview hospice patients about their fan histories, this is noted as an area for future research. In particular, her analysis poignantly shows how the dying can hold on to their identities among the living, with fandom playing a role, and also how honouring a loved one's fandom can also enable the living to hold the identities of the recently deceased, especially through personalised funeral services (which may have been specified by the departed, or requested by next of kin). Fan interests that could once have seemed eccentric in life are treated with utmost respect during funeral/memorial services; this fanbased personalization is viewed by friends and family as securing the identity coherence of their loved one, in a final iteration of commemorated self-continuity.

Despite the need to more extensively theorise children's fan practices, and to begin theorising the implications of how fandom is mobilised in relation to mortality, there can be no last words on fandom and the life course. This is especially true given the way in which the life course, as a social construct, continues to morph under neoliberal pressures, e.g. as financially well-off aging fans can experience an extended period of post-employment lifestyle consumerism. And in terms of (what would hopefully be a version of) successful aging, perhaps fan studies might, in future, be analysed via its own aca-life-course (from posited juvenilia to maturity, even if this risks plotting teleological narratives). Other areas of study which would reward further analysis from a life course perspective, as well as interviewing hospice patients, would be to gather data on the passing down of fan cultural capital, or subcultural capital, from parents to offspring (see, e.g., Nicola Smith 2013 for a useful start on this), along with tackling the issue of how normative life course transitions may be subjected to further disruptions in the face of what Kate Eichhorn (2019) has termed "the end of forgetting", i.e. the danger of one's juvenile self (and fan tastes) continuing to exist as data traces online. This could make life course transitions into 
adulthood/employment more fraught or more difficult to securely demarcate. Might our later selves (and retooled self-narratives) be increasingly troubled by our "data subject" doubles, in the guise of past self-identities? In this posited scenario, the active achievement of "adaptation" may be in danger of being overwhelmed by othered versions of previous social media selves via an excess of unwanted self-continuity.

What is meant by the life course, and how its transitions are experienced, legitimated or subjectively/communally resisted, remains open to detailed empirical analysis as well as to a range of theoretical perspectives drawn from gerontology, sociology and fan studies, with work on self-narrative having formed one key point of intersection across these disciplines. Simultaneously, what is meant by fandom is also open to rearticulation, with post-object fandom potentially being joined by a kind of post-self fandom, as fan identities are reiterated and re-performed via the instructions left in Wills, or through the memorialising gestures of friends and family within funeral services.

Neoliberalised, data-driven fandom may not yet typically accompany social agents from the cradle to the grave, but studying sociocultural developments in fandom and the life course - and especially addressing scholarly gaps in relation to childhood, generationality, and mortality - offers one direction of travel for third wave fan studies.

\section{References}

Eichhorn, Kate (2019) The End of Forgetting: Growing Up With Social Media Harvard University Press, Cambridge, MA.

Hall, Stuart and O'Shea, Alan (2015) 'Common-sense neoliberalism' in Stuart Hall, Doreen Massey and Michael Rustin (eds) After Neoliberalism: The Kilburn Manifesto Lawrence and Wishart, London: pp. 52-68.

Harrington, C. Lee and Denise D. Bielby (2010) 'A life course perspective on fandom' in International Journal of Cultural Studies 13.5, pp. 429-450. 
Harrington, C. Lee and Denise D. Bielby (2018) 'Aging, Fans and Fandom' in Melissa A. Click and Suzanne Scott (eds) The Routledge Companion to Media Fandom Routledge, New York and London: pp. 406-415.

Harrington, C. Lee, Denise D. Bielby, and Anthony R. Bardo (2011) 'Life course transitions and the future of fandom' in International Journal of Cultural Studies 14.6, pp. 567-590.

Hills, Matt (2017) “The one you watched when you were twelve": Regenerations of Doctor Who and Enduring Fandom's "Life-Transitional Objects"' in Journal of British Cinema and Television 14.2, pp. 213-230.

Martens, Marianne (2019) The Forever Fandom of Harry Potter: Balancing Fan Agency and Corporate Control Cambridge University Press, Cambridge.

Sandvoss, Cornel, Jonathan Gray and C. Lee Harrington (2017) 'Introduction: Why Still Study Fans?' in Jonathan Gray, Cornel Sandvoss, and C. Lee Harrington (eds) Fandom: Identities and Communities in a Mediated World - Second Edition New York University Press, New York and London: pp. 1-26.

Smith, Nicola (2013) 'Parenthood and the Transfer of Capital in the Northern Soul Scene' in Andy Bennett and Paul Hodkinson (eds) Ageing and Youth Cultures: Music, Style and Identity Bloomsbury Academic, London: pp. 159-172.

Williams, Rebecca (2015) Post-Object Fandom: Television, Identity and Self-Narrative Bloomsbury Academic, New York and London.

\section{Contributor Details:}

Matt Hills is Professor of Media and Film at the University of Huddersfield, UK, and director of the Centre for Participatory Culture based there. He is the author of six sole-authored 
monographs, beginning with Fan Cultures (Routledge 2002) and including The Pleasures of Horror (Continuum 2005) and Doctor Who: The Unfolding Event (Palgrave Pivot 2015). He has also edited two collections, most recently Transatlantic Television Drama (with Michele Hilmes and Roberta Pearson) for Oxford University Press (2019). Matt is a series editor, on 'Transmedia', for Amsterdam University Press, and has published widely on media fandom as well as cult film and television. He is currently working on a follow-up to Fan Cultures for Routledge, this time to be entitled Fan Studies.

Contact: Department of Media, Journalism and Film, University of Huddersfield, JM Building, Queensgate, Huddersfield, HD1 3DH, United Kingdom.

E-mail: M.J.Hills@hud.ac.uk 